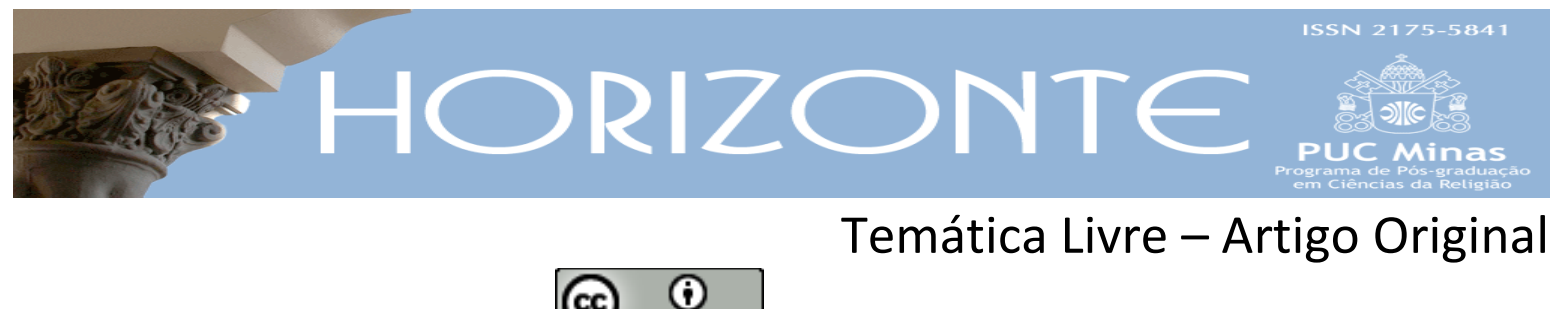

DOI - 10.5752/P.2175-5841.2020v18n56p625

\title{
Is 59,15b-21: a vinda de um redentor
}

\author{
Isa 59:15b-21: the coming of a Redeemer
}

Zuleica Aparecida Silvano*

\begin{abstract}
Resumo
Nos estudos sobre a raiz G'L, que pode ser traduzida por "resgatar" ou "manchar", "contaminar", mormente é aprofundada no Dêutero-Isaías, porém ocorre também no Trito-Isaías. Este artigo tem a intenção de analisar exegeticamente Is 59,15b-21, por meio do Método Histórico-Crítico-Literário, por ser um texto do Trito-Isaías, por descrever Deus como o "resgatador do sangue" do seu povo, como um guerreiro, cujo braço poderoso trará a justiça, e pela promessa de enviar um redentor para resgatar o povo e estabelecer uma nova Aliança, porém antes haverá destruição e calamidade. Essas intervenções divinas são consequência da falta de uma mediação que possa exercer o direito e a justiça (cf. Is 59,1-15a).
\end{abstract}

Palavras-chave: Redentor. Is 59,15b-20. Justiça. Aliança.

\begin{abstract}
In the studies about the origin of G'L which can be translated as "to redeem" or "to stain", "to contaminate", it is usually deepened in the Deutero-Isaiah as well as in the Trito-Isaiah. This article intends to do an exegetical analysis of the text (Isa 59:15b-21), through the Historical-Critical-Literary Method, by describing God as the "redeemer of His people" and as a warrior whose powerful hand will bring justice, and notwithstanding the promise of sending a redeemer to save the people and to establish a new covenant, there will be destruction and calamity beforehand. Those divine interventions are due to the lack of a mediation which can ensure righteousness and justice (cf. Isa 59:1-15a).
\end{abstract}

Keywords: Redeemer. Isa 59:15b-20. Justice. Covenant.

Artigo submetido em 16 de fevereiro de 2020 e aprovado em 18 de agosto de 2020.

*Doutora em Teologia pela FAJE. Professora da FAJE. País de origem: Brasil. E-mail: zuleica.silvano@paulinas.com.br 


\section{Introdução}

Normalmente, o radical hebraico $G^{\prime} L$ é aprofundado no Dêutero-Isaías, porém esta raiz ocorre também no Trito-Isaías (Is 59,20; 60,16; 62,12; 63,4.9.16). Uma característica peculiar do Trito-Isaías é a ocorrência das duas raízes $G^{\prime} L$ com campos semânticos diferentes. Isso se verifica em Is 59,20 e em 63,4.9.16 com o significado de "resgatar", "redimir”, enquanto sua homógrafa é utilizada em Is 59,3 e 63,3, no sentido de "contaminar", "manchar".

Este artigo objetiva analisar exegeticamente Is 59,15b-20, por meio do Método Histórico-Crítico-Literário, a fim de perceber o uso da raiz G'L no TritoIsaías. É importante aprofundá-lo dado que é citado em algumas passagens do Novo Testamento, como em 1Ts 5,8-9; Ef 6,10-17 referindo-se a Is 59,17 e dirigindo-se ao cristão e a necessidade da vigilância; e Rm 11,26-27 e At 2,38-39, para legitimar o Messianismo e a ação redentora de Jesus. Porém não iremos aprofundar essas ocorrências, visto que não é o objetivo central desse artigo. ${ }^{1}$

Ao se constatarem indícios formais, estilísticos e temáticos, alguns autores defendem a unidade literária ${ }^{2}$ e a coerência temática entre Is 56 a 66. Não obstante a falta de consenso, os argumentos para uma unidade são consistentes.

Há uma grande divergência quanto à datação do Trito-Isaías. Um ponto pacífico é a afirmação de que, possivelmente, o atual formato do livro foi definido entre os séculos II a.E.C. e I E.C., por se poder atestar sua forma final nos manuscritos de Qumran; pelas alusões e citações no Novo Testamento (JÜNGLING, 2003， p. 393-396; RIDDERBOS， 1995， p. 41-44; GARCÍA MARTINEZ, 2008).

\footnotetext{
${ }^{1}$ A ocorrência de Is 59,15b-21 nos livros do Novo Testamento foi aprofundada por Ruthven (2008a, p. 32-47; 2008b, p. 219-237; 2008); Christopher (2008, p. 119-134); Owens (2016, p. 87-103).

${ }^{2}$ Um dos aspectos formais é a inclusão presente entre os capítulos 56-66, por meio das palavras chaves: sábado (56,2.4.6 e 66,23); casa de Deus e monte santo (56,5.7 e 66,20); nome (Is 56,5 e 66,22) e a menção aos estrangeiros (56,6-8 e 66,18-21), outros elementos estilísticos foram estudados por Lack (1973, p. 120-128.142) e por Rendtorff (2009, p. 284).
} 
Quanto à datação de Is 59, por causa do vocabulário (por exemplo, a raiz $G^{\prime} L$ ), da temática e da realidade retratada, pode ser datado como pós-exílico. No entanto, determinar com precisão a datação desse capítulo é problemático pela exiguidade de informações no próprio texto, pelo longo processo redacional do livro de Isaías (RENDTORF, 2009, p. 288) e pela identificação de arranjos redacionais aglutinadores de períodos diferentes (babilônico, persa e releituras).

\section{Estrutura e gênero literário de Is 59,15b-21}

Não existe unanimidade quanto à dependência ou não do capítulo 59, do livro de Isaías, com os capítulos anteriores e posteriores ${ }^{3}$, nem quanto à subdivisão desse capítulo4. Smith une Is 58-59, reelaborando as propostas de outros comentadores, sobretudo a de Fischer. Ele assevera que esses dois capítulos formam um único poema, sendo dividido em cinco estrofes: Is 58,1-5; vv. 6-14; 59,1-8; vv. 9-15a e 15b-20. Essa afirmação é justificada pelo tema da transgressão e por referir-se a Jacó (1995, p. 97-101).

Verifica-se uma correlação entre Is 59,15b-21 e 63,1-6, observada por Muilenburg (1956, p. 687-688) e aceita por outros autores, por causa de sua similitude temática e lexical (Is 59,16 e 63,5; 59,17 e 63,1.4; GOSSE, 2001, 535547). Lynch estrutura de forma concêntrica Is 59,15b-63,6, sendo: $A=I s 59,15 b-$ 21: YHWH como guerreiro; $B=$ Is 60-62: restauração de Sião e $A^{\prime}=$ Is 63,1-6: YHWH como guerreiro. Os argumentos de Lynch são consistentes e, apesar de afirmar a afinidade entre Is 59,15b-21 e 63,1-6, mantém o Texto Massorético, dado que outros exegetas mudam a sequência dos capítulos e versículos, adaptando-os às suas análises (2008, p. 244-263).

\footnotetext{
${ }^{3}$ Há várias tentativas de estruturar o Trito-Isaías, sobretudo Is 59-64. No entanto, existe uma tendência a delimitar esses capítulos conforme a classificação do gênero literário assumido pelo comentador ou o conteúdo, em detrimento dos elementos formais e estilísticos. Por isso, assumiremos o Trito-Isaías como unidade, tendo como capítulos centrais Is 60-62. Os autores que se dedicam à delimitação do Trito-Isaías são Jüngling (2003, p. 390-391); Lack (1973, p. 125); Vermeyen (2010, p. 405-406.411) e Bachmann (2004, p. 10).

${ }^{4}$ Westermann (1978, p. 411-412) o classifica como lamentação e o subdivide em oito partes: v. 1; vv. 2-3; vv. 4-8; vv. 9-11; v. 12; vv. 13$15 a ;$ vv. $15 b-20$ e v. 21 . Croatto (2002, p. 117.138) divide Is 59 em dois grandes blocos: Is 59,1-15a e os vv. $15 b-20+o$ v. 21 , porém os subdivide em estrofes temáticas. Na primeira, identifica quatro estrofes: vv. 1-4: os pecados que rompem a relação de aliança com Javé; vv. 5-8: sobre os atos de maldade e os caminhos de violência; vv. 9-12: a confissão comunitária dos pecados, e vv. 13-15a: lista de pecados, YHWH permanece só. Subdivide a segunda parte em três unidades: vv. 15b-16: YHWH toma a decisão de agir; vv. 17-20: YHWH se veste para lutar e redimir e o v. 21: a aliança-promessa sobre o espírito e a palavra profética.
} 
A maioria dos comentadores divide Is 59 em quatro subunidades5: vv. 1-8: contém duas invectivas; vv. 9-15a: há um cântico de lamentação; vv. 15b-20: é um oráculo de salvação e Is 59,21 é um acréscimo posterior em prosa. Apesar da ausência de um consenso ${ }^{6}$ quanto à delimitação Is 59, assumiremos a separação dos vv. 15b-20 dos anteriores, por constatar uma unidade lógica. Acrescentaremos o v. 21 à perícope por causa do tema da Aliança, por conter argumentos que reportam a Is 56-58 e 59,1-20 e aos capítulos subsequentes, sobretudo, Is 60-61 e 66,22-24. Verifica-se, também, uma sequência lógica entre os conteúdos retratados nos vv. 15b-20 e o v. 21. Não obstante a certificação de que esse versículo seja uma glosa, devido ao seu estilo e conteúdo (WHYBRAY, 1981, p. 219).

Há, igualmente, discordância quanto à classificação do gênero literário deste capítulo, visto que há uma mistura de elementos característicos de vários gêneros, e nas propostas7 oferecidas pelos comentadores não é esclarecida qual é a função literária da classificação do gênero assumido (CHILDS, 2005, p. 527). Percebe-se, contudo, que há semelhança com as lamentações individuais e coletivas (WESTERMANN, 1978, p. 411). Quanto aos versículos a serem analisados, detectase ainda uma mescla de juízo de acusação e salvação, com algumas características de oráculo de salvação.

O texto de Is 59,15b-20 está correlacionado com a seção precedente, pois seu conteúdo é uma resposta eficaz à realidade exposta nos vv. 1-15a. Além desse dado, existem afinidades lexicais e temáticas, que complementam o segmento anterior (WESTERMANN, 1978, p. 420), enriquecendo-o pela densidade teológica identificada nos vv. 15b-20. Observa-se, no entanto, uma ruptura, ao assumir o estilo narrativo, apesar de manter um caráter poético. Is 59,15b-20 diferencia-se de Is 60,1-10, por causa do conteúdo, da mudança de estilo e por elementos formais.

\footnotetext{
${ }^{5}$ Esta proposta é assumida por Whybray (1981, p. 219-220); Kendall (1984, p. 393); Childs (2005, p. 526-528); Koole (2001, p. 164-166) e Blenkinsopp (2003, p. 184-203).

${ }^{6}$ Koole (2001, p. 166-170) sintetiza as críticas dos comentadores sobre a subdivisão de Is 59. Porém, não apresenta argumentos consistentes para rejeitar a unidade formada pelos vv. 15b-20.

${ }^{7}$ As principais propostas são: sermão, lamentação, oráculo de salvação, liturgia profética, invectiva profética e disputa judiciária (rîb).
} 
Is 59 inicia-se com um lamento do povo, no qual YHWH é acusado por não vir em seu socorro (v. 1; cf. 50,1-2; 58,3a; Nm 11,23 e Zc 7,11). Há uma intervenção, provavelmente do profeta, que responde à acusação exposta em Is 59,1, sublinhando que o responsável pela destruição não é YHWH, mas a iniquidade e as transgressões do próprio povo (Is 59,2-8). Essas transgressões afastam a intervenção de Deus e o cumprimento da promessa feita aos patriarcas (cf. Gn 18,18). O pecado do povo é descrito de forma genérica e metafórica, sendo especificado somente em Is 59,3.6.

Após essa acusação e a constatação da realidade, há uma confissão dos pecados, supostamente realizada pela comunidade, compilada nos moldes de uma lamentação (Is 59,9-14a). Nos vv. 14b-15a, há uma tentativa de sintetizar a situação delineada anteriormente. Ao mesmo tempo, são assumidos traços da "lamentação" ou uma “descrição de um estado negativo" (WESTERMANN, 1978, p. 418). Nesse oráculo, transparece a impossibilidade de qualquer esperança para o futuro (59,14a). Porém, ao admitir e confessar os pecados, Deus anuncia sua intervenção na história contra os adversários e se revela como o resgatador de Sião (Is 59,1620).

\section{Is 59,15b-21: tradução}

Para a tradução do texto em questão (Is 59,15b-21) foi utilizado o original em hebraico, extraído da edição crítica da Bíblia Hebraica Stuttgartensia ${ }^{8}$ (ELLIGER; RUDOLPH, 1997, 768):

15bYHWH viu e pareceu mal a seus olhos que não houvesse direito. 16Viu que não havia ninguém e espantou-se de que ninguém interviesse; então, o salvou seu próprio braço e sua justiça o sustentou.

17Vestiu-se de justiça, como de uma couraça, e pôs o capacete da salvação na cabeça; pôs sobre si a veste da vingança e se cobriu de ira ciumenta9, como de um manto.

\footnotetext{
${ }^{8}$ Não oferecemos o texto de Is 59,15b-20 em hebraico, somente uma tradução. Isto pela dificuldade que o trabalho com caracteres hebraicos traria em termos de configuração da página da revista. Porém, poderá ser verificado na obra indicada. Foram consultados o dicionário de ALONSO Schökel (2004) e a gramática de Joüon e Muraoka (2006).

${ }^{9}$ A raiz QN' não foi traduzida por "zelo", porque em português tem uma conotação positiva, o que anularia os recursos estilísticos presentes no TM (Texto Massorético), como o paralelo com o termo "vingança". A palavra "ciúme" não é adequada ao contexto. Outra possibilidade seria traduzi-lo com as palavras "cólera" ou "indignação". Esses termos pertencem ao campo semântico da revolta, da ira e não mantém o sentido de posse presente na raiz hebraica do substantivo utilizado (cf. REUTER, 2007, p. 1005-1017).
} 
${ }^{18}$ Segundo os atos, assim pagará; ira aos seus adversários e a recompensa aos seus inimigos; às ilhas, dar-lhes-á a paga ${ }^{10}$.

19Temerão, pois, desde o ocidente, o nome de YHWH e desde o nascer do sol, sua glória; pois virá como torrente impetuosa, impelida pelo espírito de $\mathrm{YHWH}^{11}$.

2oVirá um Resgatador a Sião ${ }^{12}$ e aos que retornam da transgressão em Jacó, diz YHWH ${ }^{13}$.

21Quanto a mim, esta é a minha Aliança com eles, diz YHWH: o meu espírito, que está sobre ti, e as minhas palavras, que pus na tua boca, não serão retiradas de tua boca, nem da boca da tua descendência, nem da boca da descendência de tua descendência, diz YHWH, desde agora e para todo o sempre.

\section{Organização de Is 59,15b-21}

O texto de Is 59,15b-20 segue uma sequência lógica. Deus constata a realidade de infidelidade e, ao avaliá-la, promete sua intervenção (vv. 15b-16). Sua ação inicia-se com uma preparação para o combate (v. 17); apresentação da estratégia de intervir contra o oponente (v. 18) e a favor daqueles que estão dispostos a se converterem (v. 20). Ele também anuncia sua ação (v. 19b) e a reação da terra (v. 19a). Essa sequência segue o esquema das epifanias de YHWH, que vem para retribuir com a ira os inimigos e resgatar seu povo.

Para Childs, os verbos no passado em Is 59,15b-17 têm a função de sublinhar a vontade divina de agir em defesa de seu povo e assevera que somente Deus tem o poder sobre o pecado e de agir salvificamente em favor de Sião (2005, p. 532).

Os paralelismos e outros recursos estilísticos formados pela repetição das palavras e de termos do mesmo campo semântico sugerem uma intenção estrutural. Nos vv. 15b-16a nota-se um paralelismo por expressar a reação ("pareceu mal” e "espantou-se”), a razão de tal reação, por repetir a raiz $R$ ’H ("ver”) e a partícula negativa 'ayin ("não houvesse direito”, “não havia ninguém” e

\footnotetext{
${ }^{10}$ Literalmente seria "dar o que merece", mas no sentido negativo "o castigo", a "vingança". Há diversas variantes e propostas de tradução. Optamos por manter a tradução do TM, apesar das críticas, visto que não há base textual que possa mantê-lo (cf. BARTHÉLEMY, 1986, p. 416-417). Waard assume a tradução da Sociedade Bíblica Francesa: "Il va rendre aux humains ce qu'ils ont mérité, user de furieuses représailles contre tous ses ennemis, même les plus lointains" e critica o TM (1997, p. 202-203).

${ }^{11}$ O v. 19 apresenta vários problemas de crítica textual que foram analisados por Rofé (1989, p. 407-410).

${ }^{12}$ A LXX utiliza a locução "por causa de Sião".

${ }^{13}$ Para Bachmann, por ser um texto poético e pela omissão do verbo na segunda frase, essa sentença poderia ser traduzida de duas formas. A primeira é essa pela qual optamos e a segunda seria: "e terão um oráculo de YHWH aqueles que retornam da transgressão em Jacó" (BACHMANN, 2004, p. 16-18).
} 
“ninguém que interviesse”). A repetição de frases negativas é comum em oráculos proféticos de juízo para ressaltar as práticas injustas do povo (cf. Os 4,1).

Observa-se, em Is 59,16b, um quiasmo com os verbos "salvou" e "sustentou" e os substantivos "braço" e "justiça”. Em Is 59,17, há outro quiasmo com a repetição do radical $L B S \check{S}$ (v. $17 \mathrm{~b}$ e v. $17 \mathrm{c}$ ), e o "como" (v. 17a e v. $17 \mathrm{~d}$ )14. No v. 18 , verifica-se a repetição de termos com a mesma raiz ( $g^{e}$ mûl e $g^{e}$ mûlāh) e de palavras do mesmo campo semântico ("adversários" e "inimigos"). É possível perceber um paralelismo no v. 19, com a sequência "desde o ocidente" (A), "nome" (B), Tetragrama (C) e “desde o nascer do sol" (A'), "glória" (B'), pronome possessivo (C'), e pelo zeugma com a omissão do verbo "temer" na segunda frase. Termina com um paralelismo formado pela repetição da raiz verbal $\underline{B} W^{\prime}$ (vv. 19c.20a), do Tetragrama (19d e 2ob) e pelas especificações do como e para quem virá o redentor, nos vv. 19d e $20 b$. Outro recurso estilístico é a inclusão, por meio do nome YHWH, nos vv. 15b e $20 b$.

A repetição consecutiva da mesma palavra ou raiz reforça o conteúdo nos pequenos segmentos e enfatiza o tema em questão. Os paralelismos e a sucessão de apoios semânticos propiciam uma correlação entre os versículos, gerando uma progressão lógica da temática. Os quiasmos (vv. 16cd-19ab) sublinham o contraste entre a salvação e a condenação.

No v. 21, há uma inclusão com a expressão "diz YHWH”. Além dessa locução, repetem-se os substantivos peh (4x), zera' (3x) e a partícula 'ášer (2x). Apesar de não haver perfeita sonoridade, é perceptível uma unidade sonora pela repetição dos sufixos de primeira pessoa do singular, de segunda pessoa do singular masculino e das conjugações verbais na primeira pessoa do singular.

\section{Análise literária e teológica}

A seção constituída por Is 59,15b-20 tem elementos afins com Is 50; 61,2 e 63,1-6. A locução "viu e pareceu mal a seus olhos" (Is 59,15b) remete a Gn 6,5 antes

\footnotetext{
${ }^{14}$ Vestiu-se de justiça, como de uma couraça, e pôs o capacete da salvação na cabeça; pôs sobre si a vestidura da vingança e se cobriu de indignação, como de um manto.
} 
do dilúvio, quando Deus vê a maldade do povo. Após a certificação da inexistência do direito e de um intercessor que possa salvar seu povo, Deus se dispõe a intervir. Essa disposição é expressa pelo sentido teológico do verbo "ver" (cf. Gn 6,5; Ex 3,7; Is 58,3 e 57,1; KOOLE, 2001, p. 198). A ausência do direito é constatada diante do cenário negativo descrito nos vv. 1-15a.

A palavra chave nessa perícope é mišpātt, que em hebraico pode ser traduzido por "lei” ou "juízo" e provavelmente indica uma decisão com valor normativo. Nesse sentido, relaciona-se com a palavra tôrāh (BOVATI, 2005, p. 188-191). Em Is 59, essa palavra assume vários significados (KENDALL, 1984, p. 391-405). Nos vv. 1-8, mišpāt está associado à palavra "caminho" e nos orienta para a dimensão ética e social do termo. Nos vv. 3-4, assume o caráter legal, por estar agregado tanto ao assassinato, ao derramamento de sangue, à violência física, quanto à falsidade nos tribunais (v. 4). O v. 8 afirma que pela ausência do "direito" não é possível conhecer a "paz".

O termo mišpāt é empregado em Is 59,9-15a, num contexto que retrata aspectos predominantemente religiosos, por ser vinculado ao pecado contra Deus e o próximo, e expressa a ação salvífica, sendo paralelo a "justiça” (Is 1,27; 5,7; 9,6; Sl 72,2; 89,15; 97,2) e a "salvação" (Is 59,11 e JOHNSON, 2005, p. 459-461). Esse vocábulo ou o radical da mesma raiz ( $\breve{S} P T$ ), em Is 59 , abarca tanto o sentido éticojurídico como o religioso. Sua ausência seria a total perversão nas relações com Deus e com o outro, a ausência da paz, da justiça e da salvação. Deste modo, a ação de Deus assume matizes de julgamento (salvando o inocente e punindo o ímpio) e consolida a Aliança (v. 21), rompida por causa do pecado.

Apesar do termo "direito" ter uma conotação jurídica, não se identifica com um elenco de normas, mas é, particularmente, o justo modo de proceder de Deus e deveria ser também do povo de Deus, no respeito, na fidelidade, na capacidade de oferecer e aceitar a reconciliação, na harmonia das relações intrapessoais, interpessoais, comunitárias, sociais e na justa relação com Deus. 
O espantar-se de Deus pela inexistência de um intercessor em Is 59,16, proposição presente em outros profetas ( $\mathrm{Ez} 22,30$; 39,10 e Jr 50,10), pode ser interpretado de diferentes formas. No sentido positivo, reafirma o poder de $\mathrm{YHWH}$ e, ao retomar à crítica às outras divindades, afirma que Ele é o único autor da salvação, dado que não há intermediário humano, nem intercessor divino (assegurando o monoteísmo). No aspecto negativo, pode ser compreendido no sentido de que não há nenhum justo, perante o elenco de transgressões retratado nos vv. 1-15a e a constatação de que todos são marcados pela injustiça, diferente de outros contextos nos quais há pelo menos um intercessor, como ocorre antes do dilúvio, ao apresentar o justo Noé.

Outra possibilidade seria entender o particípio (v. 16) como "não há ninguém que saia ao encontro" (CROATTO, 2002, p. 142), ou seja, não há ninguém que possa socorrer seu povo, o que seria óbvio diante da iniquidade explicitada nos versículos anteriores, mas também porque somente YHWH tem essa capacidade. Nesse sentido, é possível considerar a frase como uma forma de elucidar a falta de um intercessor no sentido de um resgatador, de alguém que possa resgatar o sangue derramado, ao perceber a violência expressa nos Is 59,3.6.7 (cf. 47,3b) e a completa ausência do direito. Portanto, a inexistência de alguém legalmente legítimo, que possa exercer a justiça, pois todos estão mergulhados na maldade (v. 14a). Nesse sentido, é significativo o emprego da raiz verbal $\underline{P} G^{\prime}$ (na forma hiphil particípio), traduzida pelo particípio antilempsómenos, na LXX, o mesmo verbo que traduz "resgatador", em Is 49,26 (RAHLFS; HANHART, 2006, 646).

O que transparece é o fracasso em todo o tipo de legalidade, ao considerar o v. 15b como o resultado do que é descrito na seção anterior (vv. 1-15a). Sobressai a falta de êxito da missão de Israel, em ser a luz entre as nações. Expressa, ainda, o fracasso da soberania divina, dado que no Oriente Médio, sobretudo em culturas presentes na Mesopotâmia, os reis se vangloriavam de sua habilidade em estabelecer e promover a "justiça e o direito" (SICRE, 1990, p. 11-103), não somente em suas terras, mas entre as nações vizinhas (Jz 5,11; 1Sm 12, 7; Mq 6,5 e Is 63,1). 
A ação salvífica expressa pelo termo "braço", no v. 16, pode ser a libertação dos pecados e a mudança da disposição interior, se considerarmos o contexto descrito nos vv. 1-15a, ou a libertação no âmbito militar, ao articular o v. 16 com o 17, sendo, portanto, o ataque ao inimigo. Provavelmente, é uma libertação interior, ética ou religiosa, descrita por meio de metáforas do campo semântico militar.

O radical $Y \breve{S}^{\circ}$ (v. 16) designa uma ação gratuita e exprime a transformação, no sentido de restaurar o relacionamento com o próprio Deus (cf. Is 46,13; 49,6 e 52,7-12).

A palavra "justiça" (v. 16) reporta-se a Is 56,1. A "justiça" adquire características retributivas, punitivas e salvíficas, ou seja, manifesta-se como juízo de salvação ou de condenação. Há uma universalização da justiça, assim não somente Israel é objeto da ação salvífica ou punitiva de Deus, mas toda a humanidade (Is 56,1-8 e 58 ).

O vestir-se, no v. 17, identifica-se com o ser de YHWH, que é caracterizado como um guerreiro (Is 42,13; 49,24-25 e 52,10), que se prepara para o combate (a couraça e o capacete), unindo a justiça e a salvação. No v. 17b, emprega-se tilbōšet um hápax legómenon, que pode ser interpretado como simples "veste". O termo mə‘̂ll, normalmente, denomina um dos trajes dos sacerdotes utilizado no culto, uma veste nupcial ou um manto real15. Contudo, pode ser interpretado como simples manto e não como uma indumentária específica. Nesse contexto, a veste e o manto são metaforicamente utilizados para representar, respectivamente, a vingança e a ira ciumenta ( $\mathrm{Nm}$ 25,11; Ez 5,13 e 16,38.42), que são termos afins (SAUER, 1982, p. 101).

O verbo "vindicar" tem como sujeito YHWH. O vindicar ou o reivindicar era uma ação legalmente regulada e vinculado ao "resgatador do sangue" (Nm 35). "Vingança" ou "vindicar" pode ser entendida como o "causar um dano a alguém em

\footnotetext{
${ }^{15}$ Cf. Ex 28,4.31.34; 29,5; 39,22; Lv 8,7; 1Sm 2,19; 15,27; 24,5.12; 28,14; 2Sm 13,18; 1Cr 15,27 e Ez 26,16. Em 1Sm 18,4 não é nítido se a referência é às vestes militares, por citar outros trajes militares, ou se é a um manto real, por serem as vestes de Jônatas. Em Is 61,10 e nas ocorrências no livro de Jó $(1,20 ; 2,12 ; 29,14)$, não é possível definir se é um manto comum ou uma indumentária específica (vestes nupciais) (cf. LEMON; PURCELL, 2019, p. 269-287).
} 
retribuição a outro dano recebido" (BOVATI, 2005, p. 46). Esse conceito emerge do pressuposto do valor absoluto da vida, por paradoxal que possa parecer. Por isso, a retribuição deve ser exata e estritamente proporcional à violação original. Só Deus tem a justa medida para julgar sem incorrer em erro (Dt 32,25). O "vindicar", como ação divina, é também uma forma de manifestar a santidade de YHWH. Deste modo, Deus é a instância justa, que restabelece e restaura a justiça, em favor, sobretudo, daqueles que mais necessitam (BOVATI, 2005, p. 48). Consequentemente, o vindicar divino no AT é visto como um "aspecto necessário na história da redenção" (SMICK, 1998, p. 999), dado que Ele não pode permitir que uma transgressão ou pecado fique sem punição (Dt 32,35.41).

Constatam-se, no Antigo Testamento, duas formas de exercício do vindicar da parte de Deus: contra os inimigos do povo ( $\mathrm{Sl} \mathrm{94)} \mathrm{e} \mathrm{em} \mathrm{oposição} \mathrm{àqueles} \mathrm{que}$ transgridem a Aliança (Lv 26,24-25). Esses sentidos estão presentes no segmento em análise de Is 59.

A força destrutiva de YHWH é identificada de forma explícita com sua ação salvífica (vv. 15b-17.20 e BAUMANN, 2011, p. 153-174). Por isso, o redator utiliza termos que retratam a potência divina (sobretudo destruidora), metáforas do campo bélico (v. 17), de juízo (v. 18), e aspectos que expressam a soberania divina sobre os elementos da natureza (v. 19). Deus, deste modo, se apresenta de forma antagônica. No entanto, o agir salvífico, a justiça, a vingança e a ira ciumenta fazem parte de Deus (por usar o verbo "vestir"), e não lhe é algo meramente contingente (cf. Is 59,16; 63,4-5; Sl 94,1 e Na 1,2-6).

No v. 17, o quiasmo enfatiza a relação entre os termos "justiça" e "ira ciumenta", "salvação" e "vingança". YHWH aparece como um guerreiro (cf. Is 42,13 e 52,10), ou, em nosso contexto, como um resgatador, vindicando contra os inimigos (vv. 17-18).

O inimigo, nos vv. 16-20, é representado como alguém externo, talvez um oponente político, o que contradiz o que foi retratado nos vv. 1-15b, no qual se assevera que o adversário é interno, ou seja, as transgressões, iniquidades, 
violências, o pecado de Israel. Porém, é possível entender a primeira palavra, "adversário", no v. 18, como um opositor externo (as nações) e a segunda, "inimigo", como alguém que pertence a Israel, mas pratica a iniquidade (Is 51,1723; SMITH, 1995, p. 124; KENDALL, 1984, p. 400; TIEMEYER, 2017,14-16).

O v. 18 é de difícil compreensão. É provável que esteja relacionado com o

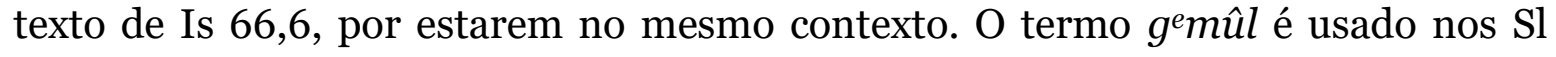
94,2; 137,8 e em Is 3,$11 ; 35,4 ; 66,6$ e está correlacionado com o reivindicar de Deus ou a retribuição divina aos seus adversários. Essa retribuição é entendida como forma de restabelecer a justiça (Sl 94,2; 28,4).

No v. 19, contém frases típicas da descrição de uma teofania, do domínio de YHWH e de sua majestade soberana (cf. Is 33,3; Sl 18,8-16), sobretudo, nos termos "nome" e "glória". A raiz verbal $Y R$ ' ("temer) pode ser interpretada tanto no sentido positivo, quanto no negativo, sendo, respectivamente, o temer reverencial diante da majestade divina ou o medo diante da manifestação potente do soberano Deus (Is 6,3; Nm 14,21; Hab 2,14). O nome da divindade exprime a revelação de sua identidade ao povo e é a garantia de sua presença redentora. Assim, o "temor" é uma reação peculiar, após a manifestação da realeza divina (cf. Is 57,11; 63,17 e 66,2b.5). O "temer o nome" era um título dado aos soberanos extraisraelitas, portanto, também salienta a dignidade régia de Deus e de seu Reino (SEMBRANO, 1996, p. 85; BAINES, 2005, p. 19-56 e LAMBERT, 2005, p. 57-74).

A concatenação entre o "nome", ou o Tetragrama, e o binômio criselibertação (Is 52,6) retrata a misericórdia divina para com seu povo oprimido (Ex 6,2.6-8). Após a libertação, evidenciada pela junção dos elementos identificados acima, emerge o convite a celebrar, adorar, conhecer e louvar o nome do Senhor para manter a memória da libertação e o despertar de um tempo novo na vida humana (cf. Jr 32,20).

A palavra "glória" equivale ao termo "nome", em algumas ocorrências (cf. Sl 102,16), visto que ambos estão associados à majestade do poder divino e à sua 
santidade (Sl 99,3; Is 6,1). Porém, nota-se que esse termo é mais abrangente, dado que engloba todas as manifestações de Deus.

A "glória" nos remete à promessa de plenificação de toda a terra com a presença divina $\left(\mathrm{Nm}\right.$ 14,21; Sl 57,6.12; 108,6) ${ }^{16}$, à salvação futura do povo em Sião (Is 24,33; 25,6-12 e 40,5) e aos julgamentos de Deus (Is 2,10; 19,21; 24,14; Ex 16,10; Nm 14,10 e 16,19).

O uso do merisma ("ocidente" e "desde o nascer do sol") enfatiza a abrangência da ação salvífica. Nesse sentido, destaca-se como intertextualidade o Sl 102,16, no qual ocorrem: a locução "temer o nome" (cf. Is 30,27; 33,3; 56,6; Dt 28,58; Ml 1,14; Sl 86,11 e Ne 1,11), o termo "glória”, representando a soberania universal (cf. Sl 99,3; Is 42,8 e 43,7), a noção de "salvação" (Is 4,5; 24,23; 40,5; 52,10), o reconhecimento reverencial a YHWH e sua ação poderosa, diante da restauração de Sião.

O "temer o nome” e a "glória” são características da vinda do Senhor, que é descrita como potência destrutiva: "como torrente impetuosa impelida pelo vento de YHWH” (v. 19). Essas expressões, além de serem típicas das teofanias (Is 6,1-3; 30,27-30; Jz 5,4-5), reportam ao início da criação diante do caos (Gn 1,2 e cf. CROATTO, 2002, p. 148), ao dilúvio (Gn 6,17; 7,17-24) e à experiência exodal (Ex 14,21-31). É perceptível uma ambiguidade na relação entre o Espírito de YHWH e a água (v. 19; cf. Is 4,4 e 32,15-20), pois a água tanto vivifica, como destrói (Is 30,2730). Essas também são as ações do Espírito, neste contexto.

\section{A vinda do resgatador a Sião e a Nova Aliança (vv. 20-21)}

A “vinda” de YHWH é um evento peculiar da tradição de Sião e da Shekînah. Ambas sustentam a possibilidade da presença divina no céu e, ao mesmo tempo, na terra, no templo. Isso é evidenciado no esforço de sábios rabinos e exegetas em demonstrar que o céu é a habitação da presença divina e onde o Deus de Israel

\footnotetext{
${ }^{16}$ Esse vocábulo é frequente em Isaías, destacam-se algumas citações: Is 3,$8 ; 10,16 ; 11,10 ; 16,14 ; 21,16 ; 24,23 ; 35,2 ; 40,5 ; 42,8.12$; 48,$11 ; 58,8 ; 60,1$ e 66,18 .
} 
reina (Sl 93,1.4; 103,19), o que possibilita entender sua vinda escatológica (URBACH, 1996, p. 43-72). Mas, sua aparição visível, sua manifestação se dá em Sião, onde YHWH tem seu trono. Deste modo, Sião se torna o centro do universo (aspecto religioso), irradiando o esplendor divino por todo o mundo (cf. Sl 48; $\mathrm{Nm}$ 14,21), ultrapassando as dimensões de espaço físico (Sl 103,19).

A cidade de Sião está relacionada também às vitórias redentoras de Deus e é o símbolo da realeza universal de YHWH (Ex 15,8-10,17; Sl 68,1-9; cf. Sl 74). Essa cidade era considerada o microcosmo de um mundo ordenado, sólido, de uma sociedade justa, fundamentada pela presença de Deus e por seus sábios decretos (Sl 68,$16 ; 89,14$ e 132,13-14). Ao partir do pressuposto de que YHWH é o Deus criador e rei universal, seus decretos deveriam servir de princípios não somente para Israel, mas para todas as nações da terra (Is 2,2-4; 51,4).

Percebe-se a tensão entre Sião e as outras nações, visto que se é possível afirmar que Sião é a "alegria de toda a terra" (Sl 48,2; 76; 97; cf. Is 42,10-13) e a portadora de bênção celestial para as outras nações (Sl 36,7-9; 65,4 e Is 61,9.11), é também vista como uma cidade inimiga (LYNCH, 2008, p. 244-263). Em Sião, Deus seria entronizado após a derrota de todos seus inimigos (Sl 29,10; 93,4; 78,66.68), por ser a cidade que o Senhor escolheu para estabelecer sua morada (Sl 48; $110 ; 125$; 132; Is 2,1-5; Mq 4,1-7 e Zc 14,16-19). Sião também era designada como lugar de refúgio dos indefesos (Sl 9,12-13; 86,1-2; Is 14,28-32 e 61,1). Uma das características peculiares da tradição de Sião era a esperança da intervenção divina (RAD, 1974, p. 186-200).

A repetição da raiz verbal $\underline{B} W^{\prime}$ chama a atenção tanto para o sentido negativo de sua vinda (v. 19b), ao remeter à vitória divina contra seus inimigos (cf. Sl 118,21-26), como para o positivo (v. 20), ao descrevê-la como evento resgatador daqueles que se convertem. Esses elementos destacam a vinda de Deus com a finalidade de julgar os povos (vv. 19b-20), expressam a revelação de YHWH, na história, como "aquele que vem" (cf. Sl 118,25-26; Is 40,10; 66,15; Zc 14,5 e PREUSS, 1988, p. 1134-1146.) e o anunciam sua vinda escatológica (Sl 96,13). O 
radical $\underline{B} W$, em seu sentido teológico, denota e garante a vinda do resgatador no sentido de julgamento, acarretando tanto a punição como a salvação.

Para Rofé (1989, p. 409), o anúncio da redenção como resultado de uma intervenção direta do Senhor na história da humanidade inicia-se em Is 54, e confirma que será um evento escatológico (cf. Is 63,1-7; 65,17; 66,22). O redentor, para esse autor, não será um notável proveniente do Império Persa, nem da descendência davídica (Is 55,3; WESTERMANN, 1978, p. 341-342) ou sacerdotal, mas um salvador-juiz. Sua função será a de fazer com que todo o mundo reverencie o Senhor YHWH e volte a cultuá-lo (ROFÉ, 1989, p. 409-410). Percebe-se, portanto, que a vitória de YHWH será ética (LYNCH, 2008, p. 256).

Em Isaías, até então, o termo "resgatador" era direcionado a YHWH (Is 41,$14 ; 43,14 ; 44,6.24 ; 47,4 ; 48,17 ; 49,7.26$ e 54,5.8). Por isso, podemos pressupor que seja o próprio YHWH que virá. Outra proposta seria supor que seria um Messias, conforme a interpretação em Rm 11,26.

O tema da conversão e o resgatador estão articulados em Is 59,20. Observase que, diante do reconhecimento do pecado, há uma mudança de atitude e, ao invés do castigo, é anunciado um resgatador que salvará aqueles que se convertem (retornam). Neste sentido, é relevante o ligame entre os radicais ŠW $\underline{B}$ e G'L, dado que nos remete a Lv 25, quando, no ano jubilar, aqueles que foram vendidos como escravos por causa das dívidas retornam para sua família e assumem suas propriedades, sendo, portanto, resgatados.

É possível afirmar que a ação redentora de YHWH abarca não só a comunidade judaica em Sião, mas também os judeus que vivem na diáspora. Mas, é necessário o retorno ao Senhor (Is 1,27-28; 6,10; 9,12; 19,22; 31,6; 44,22; 55,7 e Dt 30,1-3; cf. BERGES, 2011, p. 116.118). Conforme Polan (1986, p. 300-303), Is 59,19-20 seria a conclusão da seção iniciada em Is 56,1, e uma antecipação do que será dito em Is 60 . 
A questão que se coloca é: a conversão antecipa a redenção? Nota-se que é necessário um reconhecimento da culpa, da transgressão e, como concebem os sábios de Israel, a conversão antecipa a redenção (EL TALMUD, 2001, v. 17, 97b98a). Na LXX, a vinda do redentor provoca a conversão, conforme a tradução grega do v. 20: "Virá por causa de Sião o redentor e converterá a impiedade de Jacó" (RAHLFS; HANHART, 2006, 646). Uma conclusão viável é que são ações simultâneas, ou seja, Deus oferece sua redenção e todos são convidados a acolhê-la.

O v. 21, separado temática e literariamente dos versículos anteriores, é marcado pelas características das releituras sacerdotais, ao sustentar a promessa de uma Aliança irrevogável (Gn 6,18-19; 9,8; 17,4; cf. Is 54,9-10; 55,3 e 61,8). A Nova Aliança é, geralmente, caracterizada como algo interior, como se constata em Jr 31,31-34 e Ez 36,26-27. No v. 21, tal aspecto está presente por meio dos dons que serão concedidos: o Espírito e a Palavra (cf. Is 11,2; 42,1; 44,3; 48,16b e Jl 3,1-5), que nos remetem à missão dos profetas ( $\mathrm{Jr}$ 1,9; Is 61,1-9; Nm 11,24-30 e Jl 3,1-5) e à de Moisés (Dt 18,15-18). O Espírito é a garantia de que a promessa será cumprida, reafirmando o monoteísmo (HILDEBRANDT, 2008, p. 112). A menção ao pacto eterno reporta a Is 56,5-6 e nos remete à bênção dada a Israel (Is 44,1-6; 61,9; cf. $45,25 ; 48,18-19 ; 54,3$ e 66,22$)$.

No Dêutero e Trito-Isaías, oito passagens falam da Aliança $(42,6$; 49,8; $54,10 ; 55,3 ; 56,4.6 ; 59,21 ; 61,8)$. Em Is 42,6 , a promessa de uma Nova Aliança é dirigida ao "Servo do Senhor", no qual Deus colocará seu Espírito $(42,1.5)$. Ele será luz para as nações (v. 6) e mediador da Aliança entre Deus e o povo. Sua missão será a de implantar a justiça e libertar o povo da cegueira, das trevas, da prisão (v. 7). A "justiça", em Is 42, é vista como a relação de condescendência divina para com seu povo e a expressão da fidelidade de Deus (MERENDINO, 1983, p. 39-43). Nesse cântico, Deus se apresenta com o título de Criador (vv. 5-6). Título este que apoia e garante a nova ação redentora, vista como uma nova criação (v. 9).

A Aliança no sentido universal é retratada em Is 49,8, pois está atrelada a imagem de Deus-Criador, ao lado dos títulos: Santo e Redentor. A passagem de Is 
49,8-13 está inserida num contexto no qual é dada ênfase a "Palavra" (Is 49,2), estabelecendo um elo entre Aliança, Salvação e Redenção (Is 49,6-7).

A expressão "Aliança de Paz" ocorre no oráculo descrito em Is 54,1-10, dirigido a Jerusalém. A cidade será reconstruída e sua população retornará. A universalização da Aliança, nessa perícope, é baseada no pacto com Noé. Essa “Aliança de Paz" com Deus (v. 10) será eterna, unilateral, marcada pelo amor benevolente de YHWH.

A quarta referência à Aliança, em Is 55,3, enuncia um pacto perene e o destinatário da promessa é todo o povo (RAD, 1974, p. 283; WESTERMANN, 1978, p. 341).

Is 56,4.6 expressa a fidelidade dos eunucos e dos estrangeiros à Aliança. Deste modo, o pacto vinculado com determinadas categorias de pessoas é relativizado, por conseguinte, todas as pessoas são beneficiadas com a revelação salvífica de Deus. O critério de adesão à Aliança depende da aceitação livre e pessoal da proposta divina e da prática do direito e da justiça (Is 56,1-2 e cf. OBARA, 2010, p. 124-127).

Na quinta referência, em Is 61,8 , encontramos novamente a promessa de uma Aliança perpétua. $O$ texto descreve a vocação e a missão do mensageiro, que após receber o Espírito de JHWH é enviado a anunciar a Boa-Nova, que consiste em proclamar um ano jubilar da parte de Deus, semelhante a Lv 25,10. Em Is 61,8, percebe-se um vínculo entre o pacto perpétuo e o amor de Deus pela justiça.

Apesar de o v. 21 ser considerado glosa, se adapta ao contexto literário e aos elementos característicos da concepção de Aliança presente nas citações supramencionadas. A Aliança com Sião, referida em 59,21, aglutina a promessa

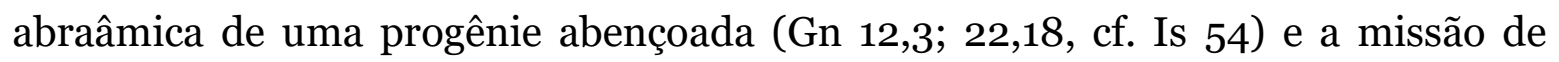
ensinar e praticar os mandamentos (cf. Dt 4,5-14). 
Nas ocorrências do termo "Aliança", no Dêutero-Isaías, não há uma referência explícita à observância da Lei, embora seja constante o convite a escutar YHWH (42,20; 44,1; 46,3; 48,1.6.12-16). Nas alusões ao Êxodo, não há, de forma direta, menção aos mandamentos, mas, sim, a manifestação da onipotência divina. Essa ausência pode ser justificada pela situação de Israel após a dominação babilônica (sem lei, sem templo, sem rei e sem Estado, cf. Is 59,1-15a), podendo contar somente com a benevolência gratuita de Deus e com sua proteção (LYNCH, 2008, p. 247-263). Assim, a Nova Aliança será semelhante às Alianças estabelecidas com Abraão e Noé (unilateral, incondicionada e gratuita), por causa da infidelidade do povo (cf. Is 59,1-11) e será universal.

Childs chama a atenção para a relação existente entre a temática do pecado no Proto e no Trito-Isaías, diferenciando-se do Dêutero, ou seja, o Dêutero-Isaías apresenta o pecado como uma realidade do passado, o Proto e o Trito-Isaías consideram todo Israel pecador no presente (2005, p. 529-530). Outro aspecto a ressaltar é que Deus não pode compactuar com a injustiça. Isso é perceptível no uso dos termos "vindicação", "ira ciumenta" (v. 17) e nas afirmações dos vv. 18-19.

Apesar das afinidades entre Is 59,21 e a tradição deuteronomista, é inegável a influência da releitura sacerdotal, identificável nos paralelos com Lv 26; Ez 18,2132 e 33,1-20.

\section{Conclusão}

Ao sintetizar as características peculiares do uso da raiz hebraica $G^{\prime} L$ em Is 59,15b-21, percebe-se que no Trito-Isaías predomina o uso desse radical para retratar o resgate do pecado, da injustiça, das transgressões, da aflição (Is 64,9) e o estabelecer o direito e a justiça. É enfatizada, ainda, a necessidade de uma Nova Aliança, a relação entre o envio do Espírito e a Palavra (Is 59,21), bem como, a santidade e a ação redentora e misericordiosa de Deus. Nota-se uma forte influência da tradição exodal, de Sião e o foco no Templo, ao indicar que a manifestação de Deus e de sua ação redentora serão em Jerusalém. 
O goelato é utilizado de forma metafórica, predominando os elementos relacionados ao "resgatador do sangue". Deus como resgatador tem a função de reivindicar o sangue derramado de seu povo e, ao resgatá-lo, manifesta sua "justiça". A justiça é vista como a garantia de um espaço de relações, que edificam e conservam a comunhão entre as pessoas e com Deus. A justiça de Deus coincide com sua ação redentora, e faz parte de sua gratuidade e de sua ação misericordiosa. O "reivindicar" é uma forma de expressar a santidade divina e é um aspecto necessário da ação redentora, porque Deus não pode permitir que uma transgressão permaneça sem punição.

A ação redentora de Deus está ligada ao seu julgamento, não somente das nações, mas, sobretudo, de Israel, diante de sua infidelidade à Aliança. Mas ressalta a ação redentora e gratuita de Deus e não a punição e o castigo. No entanto, é necessário o retorno de Israel ao Senhor. Essa ação redentora será universal e o autor estabelece uma relação entre Redenção, Eleição, Aliança, apresentando-as como categorias de uma mesma ação solidária de Deus.

Existe, igualmente, uma correlação entre Is 59 e $\mathrm{Rm} \mathrm{1-3,} \mathrm{de} \mathrm{forma}$ particular pela sequência dos fatos: a acusação dos pecados, a confissão da culpa (Is 59,1-15a e Rm 1,18-3,20) e, ao invés da condenação, a intervenção divina (Is 59, 17-19 e Rm 3,21-26), a vinda de um redentor (Is 59,20) e a Aliança (59,21). Paulo, em Rm 11,26-27, serve-se de Is 59,20, porém muda a frase ao colocar a expressão "de Sião", referindo-se a Jesus Cristo e ao unir Is 59,20-21. O Apóstolo provavelmente o utiliza por ser o único texto no qual se afirma que YHWH enviará um redentor, que, para Paulo, é Jesus, o Messias, o Senhor. Essa perícope legitima o argumento paulino, de que a Nova Aliança será gratuita, incondicional, irrevogável e a vinda do Messias se dará por uma intervenção direta de Deus na história, ao enviar o seu Filho para revelar o amor, a misericórdia e a justiça divina, e ao se encarnar, também, redime a humanidade. 


\section{REFERÊNCIAS}

ALONSO SCHÖKEL, L. M. Dicionário bíblico hebraico-português. 3. ed. São Paulo: Paulus: 2004.

BACHMANN, M. G. iSi hubiera mediaciones! (Isaías 59:15-16). Cuadernos de Teología, Buenos Aires, v. 23, p. 9-22, 2004.

BAINES, J. A realeza egípcia antiga: formas oficiais, retórica, contexto. In: DAY, J. (Org.). Rei e messias em Israel e no Antigo Oriente próximo: dissertações do seminário veterotestamentário de Oxford. São Paulo: Paulinas, 2005. p. 19-56. (Bíblia e História. Série Maior).

BARTHÉLEMY, D. Critique textuelle de l'Ancien Testament: Isaïe, Jérémie, Lamentations. Fribourg (Suisse): Editions Universitaires; Göttingen: Vandenhoeck \& Ruprecht, 1986. v. 2. (Orbis Biblicus et Orientalis, 50).

BAUMANN, G. Entender as imagens divinas da violência no Antigo Testamento. São Paulo: Loyola, 2011.

BERGES, U. Isaías: el profeta y el libro. Estella (Navarra): Verbo Divino: 2011. (Estudios Bíblicos, 44).

BLENKINSOPP, J. Isaiah 56-66: a new translation with introduction and commentary. New York: Doubleday, 2003. (The Anchor Bible, 19B).

BOVATI, P. Ristabilire la giustizia: procedure, vocabolario, orientamenti. Roma: Pontificio Istituto Biblico, 2005. (Analecta Biblica, 110).

CHILDS, B. S. Isaia. Brescia: Queriniana, 2005. (Commentari Biblici).

CHRISTOPHER R., Bruno. The deliverer from Zion: the source(s) and function of Paul's citation in Romans 11:26-27. Tyndale Bulletin, Cedarville, v. 59, n. 1, p. 119-134, 2008 e

CROATTO, J. S. Isaías: a palavra profética e sua releitura hermenêutica. Is 5666: a utopia da nova criação. Petrópolis: Vozes, 2002. v. 3. (Comentário Bíblico. AT).

EL TALMUD DE BABILONIA: Tratado Sanedrín. Buenos Aires: Acervo Cultural, 2001. v. 17 .

ELLIGER, K.; RUDOLPH, W. (Ed.). Biblia Hebraica Stuttgartensia. $5^{\text {nd }}$ ed. Stuttgart: Deutsche Bibelgesellschaft, 1997.

GARCÍA MARTINEZ, Florentino. Textos de Qumran: edição fiel e completa dos documentos do Mar Morto. Petrópolis: Vozes, 1995. 
GOSSE, Bernard. Isa 63,1-6 en relation à la synthèse du livre d'Isaïe en mšp ${ }^{\dagger}$ cdqh/ yšweh cdqh, et la place d'Isa 34-35 dans la rédaction du livre. Zeitschrift für die Alttestamentliche Wissenschaft, Berlin, v. 113, n. 4, p. 535-552, Dez. 2001.

HILDEBRANDT, W. Teologia do Espírito de Deus no Antigo Testamento. São Paulo: Academia Cristã; Loyola, 2008.

JOHNSON, B. mišpāṭ. In: BOTTERWECK, G. J.; RINGGREN, H.; FABRY, H.-J. (A cura di). Grande Lessico dell'Antico Testamento. Brescia: Paideia, 2005. v. 5, p. 450-466.

JOÜON, P.; MURAOKA, T. Gramática del hebreo bíblico. Estella (Navarra): Verbo Divino, 2006.

JÜNGLING, H.-W. O livro de Isaías. In: ZENGER, E.; BRAULIK, G. et al. Introdução ao Antigo Testamento. São Paulo: Loyola, 2003. p. 388-392. (Bíblica Loyola, 36).

KENDALL, D. The use of Mišpaț in Isaiah 59. Zeitschrift für die Alttestamentliche Wissenschaft, Berlin, v. 96, n. 3, p. 391-405, 1984.

KOOLE, J. L. Isaiah III: 56-66. Leuven: Peeters, 2001. v. 3, p. 162-214. (Historical Commentary on the Old Testament).

LACK, R. La symbolique du livre d'Isaïe. Roma: Biblical Institute Press, 1973. (Analecta Biblica, 59).

LAMBERT, W. G. A realeza na antiga Mesopotâmia. In: DAY, J. (Org.). Rei e messias em Israel e no Antigo Oriente próximo: dissertações do seminário veterotestamentário de Oxford. São Paulo: Paulinas, 2005. p. 57-74. (Bíblia e História. Série Maior).

LEMON, Joel M.; PURCELL, Richard A. The Garments of God: Iconographic Case Studies from Isaiah 6:1; 59:17; and 63:1-6 Joel. In: BERNER, Christoph; SCHÄFER, Manuel; SCHOTT, Martin; SCHULZ, Sarah; WEINGÄRTNER, Martina. Clothing and Nudity in the Hebrew Bible. London: T\&T Clark, 2019. p. 269-288.

LYNCH, M. J. Zion's warrior and the nations: Isaiah 59,15b-63,6 in Isaiah's Zion traditions. The Catholic Biblical Quarterly, Washington, v. 70, n. 2, p. 244-263, Apr. 2008.

MERENDINO, R. P. Il dono dell'alleanza (Is 40-48). Parola, Spirito e Vita, Bologna, n. 7, p. 36-5O, 1983 .

MUILENBURG, J. The book of Isaiah: chapters 40-66. In: BUTTRICK, G. A. The interpreter's Bible: the Holy Scriptures in the King James and revised standard versions with general articles and introduction, exegesis, exposition for each book of the Bible. New York: Abdingdon-Cokesbury Press, 1956. v. 5, p. 687-688.

OBARA, E. M. Le strategie di Dio: dinamiche comunicative nei discorsi divini del TritoIsaia. Roma: Gregorian \& Biblical Press, 2010. (Analecta Biblica, 188). 
OWENS, Mark D. Spiritual warfare and the church's mission according to Ephesians 6:1017. Tyndale Bulletin, Cedarville, v. 67, n. 1, p. 87-103, 2016.

POLAN, G. J. In the ways of justice toward salvation: a rhetorical analysis of Isaiah 56-59. New York: Peter Lang, 1986. (American University, 7. Theology and Religion, 13).

PREUSS, D. H. Bô'. In: BOTTERWECK G. J.; RINGGREN, H. (A cura di). Grande Lessico dell'Antico Testamento. Brescia: Paideia, 1988. v. 1, p. 1084-1146.

RAD, G. von. Teologia dell'Antico Testamento: teologia delle tradizione profetiche d'Israele. Brescia: Paideia, 1974. v. 2. (Biblioteca Teologica, 7).

RAHLFS, A.; HANHART, R. (Ed.). Septuaginta. ed.alt.q.recog. et emed. Stuttgart: Deutsche Bibelgesellschaft, 2006.

RENDTORFF, R. Antigo Testamento: uma introdução. Santo André: Academia Cristã, 2009.

REUTER, E. qn'. In: BOTTERWECK, G. J.; RINGGREN, H.; FABRY, H.-J. (A cura di). Grande Lessico dell'Antico Testamento. Brescia: Paideia, 2007. v. 7, p. 1005-1017.

RIDDERBOS, J. Isaías: introdução e comentário. 2.ed. São Paulo: Vida Nova, 1995. (Comentários Bíblicos. Cultura Bíblica, 17).

ROFÉ, A. Isaiah 59:19 and Trito-Isaiah's vision of redemption. In: VERMEYLEN, J. (Ed.). The book of Isaiah - Le livre d'Isaïe: les oracles et leurs relectures. Unité et complexité de l'ouvrage. Leuven: University Press, 1989. p. 407-410. (Biblioteca Ephemeridum Theologicarum Lovaniensium, 81).

RUTHVEN, Jon. 'This Is My covenant with them': Isaiah 59.19-21 as the programmatic prophecy of the new covenant in the Acts of the Apostles (Part I). Journal of Pentecostal Theology, Leiden, v. 17,n. 1, p. 32-47, 2008.

RUTHVEN, Jon. 'This Is My covenant with them': Isaiah 59.19-21 as the programmatic prophecy of the new covenant in the Acts of the Apostles (Part II). Journal of Pentecostal Theology, Leiden, v. 17, n. 2, p. 219-237; 2008.

SAUER, G. nqm. In: JENNI, E.; WESTERMANN, C. (Org.). Dizionario Teologico dell'Antico Testamento. Casale Monferrato: Marietti, 1982, v. 2, p. 98-101.

SEMBRANO, L. Le immagini della regalità nei Salmi. In: FARRUGIA, M. (A cura di). Universalità del Cristianesimo: in dialogo con Jacques Dupuis. Cinisello Balsamo: San Paolo, 1996. p. 85.

SICRE DÍAZ, J. L. A justiça social nos profetas. São Paulo: Paulinas, 1990. (Nova Coleção Bíblica). 
SMICK, E. B. nāqam. In: HARRIS, L. R. (Org.). Dicionário Internacional de Teologia do Antigo Testamento. São Paulo: Vida Nova, 1998. p. 999-1001.

SMITH, P. A. Rhetoric and redaction in Trito-Isaiah: the structure, growth and authorship of Isaiah 56-66. Leiden: Brill, 1995. (Supplements to Vetus Testamentum, 62).

TIEMEYER, Lena-Sofia. Death or conversion: the gentiles in the concluding chapters of the book of Isaiah and the book of the twelve. The Journal of Theological Studies, Oxford, v. 68 n. 1 p. 1-22. Apr 2017.

VERMEYLEN, J. Isaías. RÖMER, T.; MACCHI, J.-D.; NIHAN, C. (Org.). Antigo

Testamento: história, escritura e teologia. São Paulo: Loyola, 2010. p. 401-418.

WESTERMANN, C. Isaia (Capp. 40-66). Brescia: Paideia, 1978. (Antico Testamento, 19).

WHYBRAY, R. N. Isaiah 40-66: based on the revised standard version. London; Grand Rapids: Morgan \& Scott; Marshall: Eerdmans, 1981. (New Century Bible Commentary). 